\title{
Erratum in: Cost per responder for upadacitinib vs abatacept in patients with moderate-to-severe Rheumatoid Arthritis in Italy
}

\section{Roberto Caporali ${ }^{1}$, Roberto Ravasio², Paola Raimondo², Fausto Salaffi ${ }^{3}$}

${ }^{1}$ Department of Clinical and Community Science (DISCCO), University of Milan and Department of Rheumatology and Medical Science, ASST Pini-COT, Milan - Italy

${ }^{2}$ Market Access Provider, Milan - Italy

${ }^{3}$ Rheumatology Clinic, "Carlo Urbani" Hospital, Department of Clinical and Molecular Science, Università Politecnica delle Marche, Jesi (AN) - Italy

In the article "Cost per responder for upadacitinib vs abatacept in patients with moderate-to-severe Rheumatoid Arthritis in Italy", (1) which appeared in Volume 8, Issue 1 of Global \& Regional Health Technology Assessment, the values appearing in Fig. $5 \mathrm{C}$ and $\mathrm{D}$, inadvertently repeated the values reported in Fig. $5 \mathrm{~A}$ and $\mathrm{B}$. Affected data have been corrected in the article now appearing online. The authors apologize for any inconvenience caused to the readers by these changes, which do not affect the final results of the study.

The final version of this article is available online and includes a reference to this correction.

\section{Reference}

1. Caporali R, Ravasio R, Raimondo P, Salaffi F. Cost per responder for upadacitinib vs abatacept in patients with moderateto-severe Rheumatoid Arthritis in Italy. Glob Region Health Technol Assess. 2021;8:69-79. CrossRef

Received: February 9, 2022

Accepted: February 11, 2022

Published online: February 17, 2022

Corresponding author:

Roberto Ravasio

Market Access Provider Srl

Via Vincenzo Monti 3

20123 Milano - Italy

ravasio@maprovider.com 